Prospective Trial

\title{
Improving the Safety of Transforaminal Epidural Steroid Injections in the Treatment of Cervical Radiculopathy
}

David S. Kloth, MD', Aaron K. Calodney, MD², Richard Derby, MD³, Francis P. Lagattuta, MD4, Conor O'Neill, MD', Elizabeth Yurth, $\mathrm{MD}^{6}$, Larry E. Miller, PhD ${ }^{7,8}$, and Jon E. Block, PhD

From: ${ }^{2}$ Connecticut Pain Care, Danbury, CT; ${ }^{2}$ NeuroCare

Network, Tyler, TX; 3 Spinal Diagnostics \& Treatment Center,

Daly City, CA; 4 Lags Spine \&

Sportscare, Santa Maria, CA;

sCalifornia Spine Diagnostics,

San Francisco, CA; ${ }^{6}$ Mapleton

Hill Orthopaedics; Boulder, CO; ${ }^{7}$ Miller Scientific Consulting, LLC Flagstaff, AZ; ${ }^{8}$ on E. Block, Ph.D., Inc., San Francisco, CA

Address correspondence: Jon E. Block, PhD 2210 Jackson Street, Suite 401

San Francisco, CA 94115 Email: jonblock@jonblockphd.

com

For detailed disclosures, see page 291.

Manuscript received: 09/23/2010 Revised manuscript received: $02 / 11 / 11$

Accepted for publication: 03/15/11

Free full manuscript: www.painphysicianjournal.com
Background: Unplanned vascular trespass occurs in $20 \%$ of cervical transforaminal epidural steroid injections (CTFESI) and rarely results in devastating neurologic complications. The Trucath Spinal Injection System is a novel integrated catheter and needle device that is specifically designed to minimize vascular trespass risk.

Objective: To compare the vascular trespass incidence with the Trucath Spinal Injection System versus standard spinal needles during CTFESI treatment in patients with cervical radiculopathy.

Study Design: Prospective, multicenter, nonrandomized safety trial.

Setting: Six tertiary spinal pain management centers in the United States.

Methods: We treated 290 patients (411 levels) with recalcitrant cervical radiculopathy using CTFESI; 129 patients (180 levels) were treated with the Trucath Spinal Injection System (Test group) and 161 patients (231 levels) were treated with standard spinal needles (Control group). All injections were administered via a transforaminal approach. Each site attained IRB approval for this study before any research was performed. The primary study endpoint was vascular trespass per treated level. Secondary endpoints included nerve pain or paresthesia, injection accuracy, device performance measures, and procedural adverse events.

Results: Vascular trespass occurred more often (odds ratio (OR): 3.1, 95\% Confidence Interval $(C \mathrm{l}): 1.8-5.4, P<0.001)$ in Controls $(26.8 \%, 62 / 231$ levels) versus Test patients $(10.6 \%, 19 / 180$ levels). Radicular pain or paresthesia from device positioning was more frequent (OR: $21.1,95 \%$ Cl: 6.9-64.5, $P<0.001)$ in Controls $(26.4 \%, 61 / 231)$ versus Test participants $(1.7 \%, 3 / 179)$. Inadequate epiradicular flow was observed in $3.0 \%$ (7/231) of Controls and $5.6 \%(10 / 179)$ of Test participants (OR: $0.5,95 \% \mathrm{Cl}: 0.2-1.4, P=0.22$ ). Based on subjective physician judgment (scale: 1-10), there were no differences between the Test and Control groups, respectively, for ease of use (mean 8.9 vs. 9.0), visualization under fluoroscopy (mean 9.2 vs. 9.0), and overall performance (mean 9.0 vs. 8.6). No additional adverse effects were reported in either treatment group in this clinical study.

Limitations: The study did not randomly allocate the type of injection procedure to participants and no clinical outcomes beyond the initial treatment were collected.

Conclusions: The Trucath Spinal Injection System demonstrated a statistically significant reduction in the rate of intravenous and intra-arterial trespass, procedural pain, and paresthesia, and has similar accuracy and performance versus standard spinal needles for CTFESI treatment of cervical radiculopathy.

Key words: cervical, epidural, radiculopathy, steroid, transforaminal, Trucath, vascular trespass

Pain Physician 2011; 14:285-293 
ervical radiculopathy is a condition that affects 1 in 1,000 people each year (1) and is characterized by unilateral or bilateral arm pain with or without neck pain, often accompanied by numbness and tingling of the affected extremity, that results from irritation of a cervical spinal nerve and/ or the nerve roots (2). Cervical spondylosis and disc herniation are the most common causes of cervical nerve root compression. The initial treatment for cervical radiculopathy is conservative care, although gradual progression to more invasive treatments is necessary in recalcitrant cases. Conservative care options include activity modification, analgesics, nonsteroidal anti-inflammatory medications, and physical therapy. However, clinical success rates with these therapies are less than satisfactory and more than 1 in 4 patients will ultimately require surgery in an effort to achieve symptomatic relief (1). Unfortunately, surgery entails inherent risks and results in only moderate long-term benefit versus conservative management $(3,4)$ with almost 1 in 3 patients experiencing recurring cervical radicular pain following surgery (1). Clearly, there is a great need for effective, minimally-invasive treatments to bridge the continuum of care between conservative management and surgery in cervical radiculopathy.

Epidural steroid injections (ESI) offer an intermediate and reasonable step in the continuum of care for radiculopathy in patients who are unresponsive to prolonged conservative management (5-17). The rationale for treatment with a cervical epidural steroid injection (CESI) is that direct and specific corticosteroid administration precisely to the area of root compression/irritation will relieve the inflammation of the spinal nerve and its roots. Several randomized, prospective (17-23), retrospective (24-28) studies, a systematic review (10), and guidelines $(5,6)$ have reported favorable long-term patient outcomes with cervical epidural steroid injections. Cervical transforaminal epidural steroid injections (CTFESI) are particularly appealing since they require only a small injectate volume and directly target the primary pathology site, which is commonly in the foraminal region. However, this procedure is not without risk. Perhaps the most notable risk associated with CTFESI is vascular trespass, or unplanned injection into a vein or artery. Although vascular trespass incidence during CESI is about $20 \%$ (29), resulting clinical sequelae are uncommon $(0.3-1.7 \%)(30,31)$. Nonetheless, serious events such as seizure, infarction of the brainstem or spinal cord, and death, presumably caused by vascular trespass with resultant distal embolization of particu- late steroid, have been reported with transforaminal as well as interlaminar CESI approaches (32-34).

The Trucath Spinal Injection System (Smith \& Nephew, Inc., Memphis, TN) is a novel device that is specifically designed to minimize vascular trespass risk during CTFESI. The primary objective of this study was to compare procedural safety of the integrated catheter and needle system versus standard spinal needles for CTFESI treatment in patients with cervical radiculopathy. The device is designed with a catheter integrated into a conventional spinal needle that allows the tip of the needle to be positioned away from sensitive structures such as nerves and blood vessels prior to advancing the catheter from the needle tip and into the epidural space. Given the unique design of the system, we hypothesized that the vascular trespass rate would be lower in patients treated with the integrated catheter and needle system versus those treated with standard spinal needles.

\section{Methods}

\section{Patients}

This study was a prospective, multicenter, nonrandomized safety trial that was conducted at 6 investigative sites in the United States. Prior to patient enrollment in the clinical study, each study investigator performed a minimum of 10 training cases in patients using a standardized technique with the integrated catheter and needle system. A total of 290 patients (411 levels, 1.4 levels/patient) were enrolled in the study; 129 (180 levels, 1.4 levels/patient) were treated with the integrated catheter and needle system (Test group) and 161 (231 levels, 1.4 levels/patient) were treated with standard commercially available spinal needles (Control group). Participants were treated between August 2008 and November 2009. At each investigative site, participant enrollment in a treatment group was completed before treatment allocation alternated to the other treatment group. This nonrandomized method of enrollment was utilized to determine the most precise estimate of vascular trespass and adverse event incidence rates over a large consecutively treated sample for each injection method, while employing the same group of highly experienced physician operators.

The single inclusion criterion of this trial was clinical signs and symptoms of cervical radiculopathy unresponsive to conservative management, i.e. upper extremity radicular pain regardless of corresponding neurological loss, or imaging evidence of neural impingement 
caused by stenosis and/or disc pathology at the index level. Exclusion criteria included anticoagulant or antiplatelet medication usage (other than low-dose acetylsalicylic acid therapy) within 5 days of the procedure, untreated bleeding disorders, pregnancy, tortuous vertebral artery, anatomic anomaly of the foramen transversarium, and history of vascular-related cervical injury secondary to cervical injection procedure.

The study protocol was approved by Western Institutional Review Board (Olympia, WA) and each patient provided informed consent before any study procedures were initiated.

\section{Measurements}

Baseline assessments included a complete physical examination with medical history, biplanar radiography, and magnetic resonance imaging, which were used to select the treated level(s). Vascular trespass was defined as contrast in a blood vessel (artery or vein) visualized under real-time fluoroscopy or retrograde blood observed in the device (spontaneously or following aspiration with a syringe). Intra-arterial trespass was identified by rapid contrast clearance from the injection site along the course of the vessel; cephalad flow indicates vertebral artery infiltration and medial flow implies radicular artery injection. Vascular trespass frequency was calculated based on the total number of treated levels. Nerve pain, or paresthesia, was defined as patient-reported pain and/or tingling at or near the injection site or in distribution concordant with the affected nerve during device or needle positioning. Adequacy of epiradicular flow was evaluated by confirmation of media injection into the epidural space. Device malfunction was defined as any device-related event that necessitated use of a new injection needle or termination of the procedure. Physicians subjectively evaluated device performance based on 3 parameters: ease of use, visualization under fluoroscopy, and overall performance. Data were recorded on a 1-10 scale with a higher value indicating greater performance. Safety was assessed by calculating the incidence of procedural adverse events, which were classified as serious or nonserious and by relatedness to the device.

\section{Device Description}

Commercially available, 25-gauge, 1.5 - to 3.5inch needles were used for all injections in Control participants.

The Trucath System consists of a flexible, retractable 25-gauge injection catheter and a 1.8 inch 22-gauge

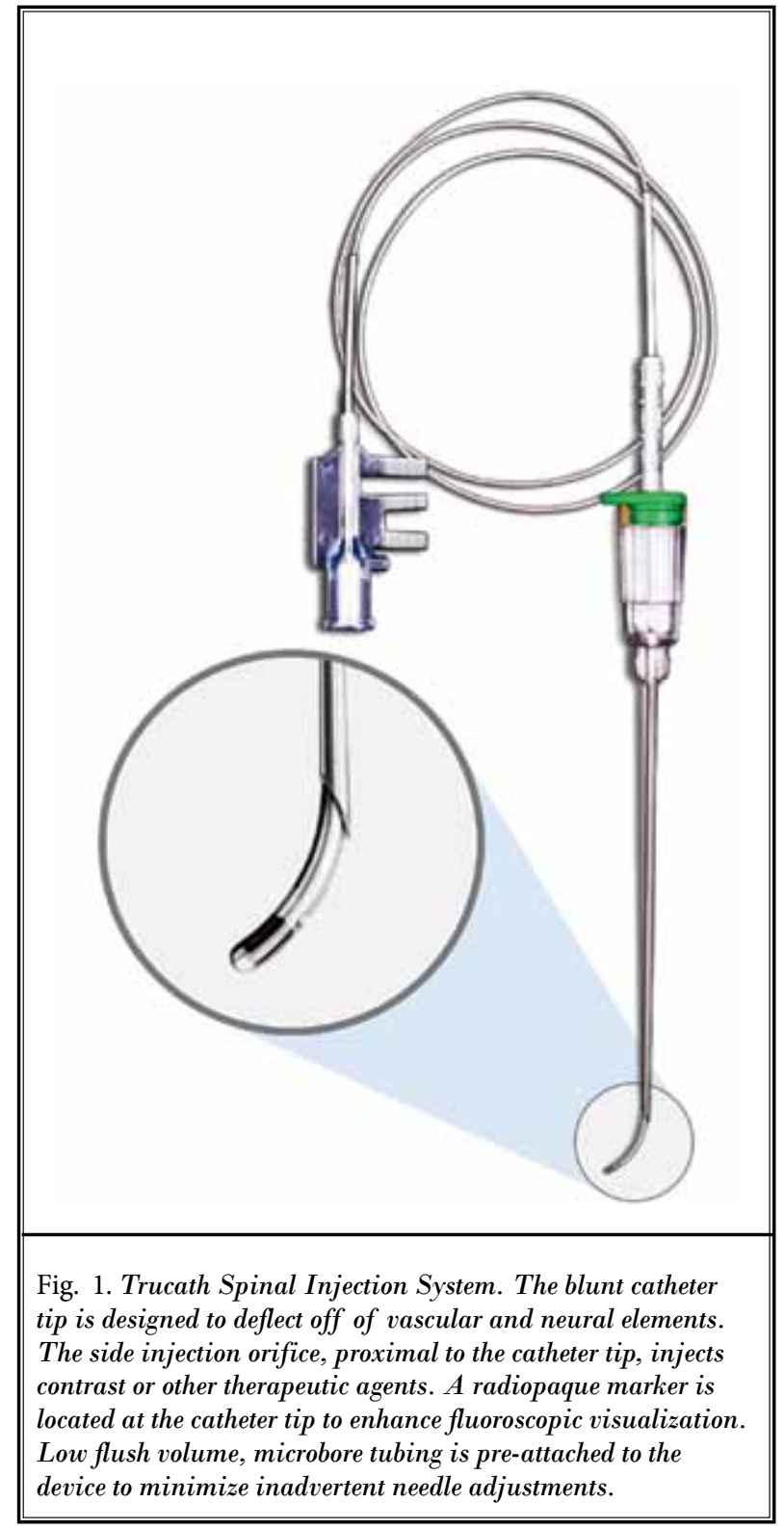

Quincke point spinal needle designed for injection into the epidural space (Fig. 1). The injection catheter is integrated with the needle as one device and is passed through the inside of the hypodermic needle to a maximum of $7 \mathrm{~mm}$ distal to the needle tip. The injection catheter is advanced from the needle tip along a curved path and has an easily visible radiopaque marker at the blunt distal end and an injection orifice positioned on the outer curvature $2 \mathrm{~mm}$ proximal to the tip. This unique design allows the catheter to be positioned beyond the reach of conventional needles 
and allows medication distribution proximal to the distal tip of the catheter to further reduce risk of vascular or nerve injection (Fig. 2). An end cap with a directional arrow is located on the needle body and points in the direction that the catheter will go when deployed. The curved catheter tip allows for directional positioning of the catheter into the area of pathology or in the epidural space as desired by the physician.

\section{Procedural Details}

For all procedures, regardless of the injection needle that was used, CTFESI was performed. The participant was prepped and draped in the usual manner. The participant was then placed in a supine, oblique, or lateral decubitus position based on the individual preference of the investigator and adjusted so that the foramen was perpendicular to the fluoroscope. The fluoroscope was then adjusted to visualize the cervical spine with a focus on the target intervertebral foramen. A spinal needle was advanced to the posterior aspect of the foramen (Fig. 2). From here, the needle was advanced to the mid-sagittal line of the articular pillar. The needle was withdrawn slightly and/or repositioned if the patient experienced pain or paresthesia in the scapula or upper extremity. For procedures performed with the integrated catheter and needle system, the needle was advanced to the lateral aspect of the foramen. After confirmation of needle position with fluoroscopy, the catheter was deployed from the lumen of the needle into the foramen by advancing the plunger

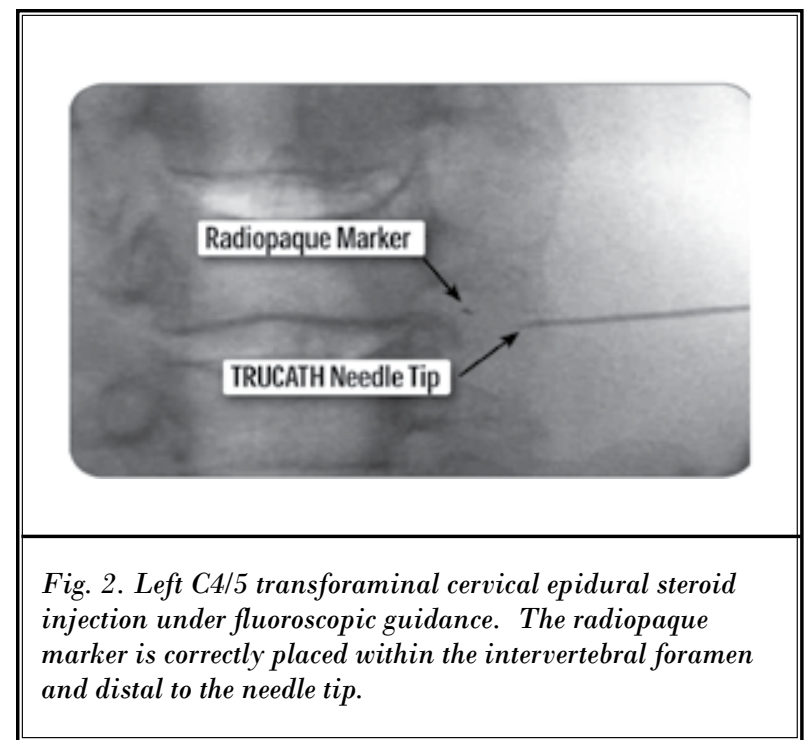

attached to the needle body.

A syringe filled with non-ionic contrast material was used to flush the connected microbore tubing prior to placement in the patient. After confirmation of proper needle and catheter placement, non-ionic contrast material was injected to confirm epiradicular flow and to identify vascular infiltration. If intravascular contrast was observed, the catheter and/or needle tip was adjusted and contrast material was injected again to confirm epiradicular flow without vascular uptake/trespass. Some physicians, after confirmation of accurate epiradicular flow, injected a test dose of a short-acting local anesthetic (e.g., lidocaine) in order to identify any neurologic deficit concordant with intra-arterial injection. If the patient reported no complications such as oral numbness, shortness of breath, agitation, or paraparesis, then corticosteroid (e.g., dexamethasone $4 \mathrm{mg} /$ $\mathrm{mL}$ of betamethasone) was injected to complete the procedure.

\section{Patient Follow-up}

The objective of this trial was to assess procedural outcomes of CTFESI with the integrated catheter and needle system versus standard spinal needles. Therefore, participants were discontinued from the trial immediately following the CTFESI procedure and no clinical follow-up data were collected.

\section{Statistical Methods}

A sample size of 231 Control levels and 180 Test levels provided $90 \%$ statistical power to detect an odds ratio of 2.5 or greater for vascular trespass frequency in Control versus Test participants, assuming a $19.4 \%$ Control group incidence (15). Statistical comparisons between treatment groups were performed with independent samples t-tests for continuous measures and Fisher's exact test for nominal variables. Odds ratios (OR) of Control vs. Test particpants and associated 95\% confidence intervals $(\mathrm{Cl})$ were calculated by logistic regression.

\section{Results}

All CTFESIs were completed successfully and procedural data were available for all participants. No investigative site contributed more than $30 \%$ of the total levels in either the Test or Control groups.

\section{Vascular Trespass}

The incidence of vascular trespass was notably higher (OR: 3.1, 95\% Cl: 1.8-5.4, $P<0.001$ ) in Controls 
(26.8\%, 62/231 levels) versus Test patients (10.6\%, 19/180 levels) (Fig. 3). Vascular trespass rates were consistently higher in Control participants, regardless of injection location (Table 1). The incidence of intra-arterial injection was also higher $(P=0.02)$ in Controls $(3.0 \%$, $7 / 231$ levels) compared to Test participants $(0 \%, 0 / 180$ levels).

\section{Secondary Outcomes}

The frequency of operative nerve pain or paresthesia was dramatically higher (OR: $21.1,95 \% \mathrm{Cl}: 6.9-64.5$, $P<0.001)$ in Controls $(26.4 \%, 61 / 231)$ versus Test participants $(1.7 \%, 3 / 179)$. Inadequate epiradicular flow was similar between the groups with $3.0 \%$ (7/231) in Controls and 5.6\% (10/179) in Test participants (OR: 0.5, 95\% Cl: $0.2-1.4, P=0.22)$. Reports of device malfunction were similar $(P=0.08)$ between Control $(0 \%, 0 / 231)$ and Test $(1.7 \%, 3 / 178)$ groups (Fig. 4). Each of the 3 device malfunctions in the Test group was related to kinking of the deployed catheter.

Qualitative assessments of device performance imply that the integrated catheter and needle system performed well and was rated similar to standard spinal needles for ease of use (mean 8.9 vs. 9.0), visualization under fluoroscopy (mean 9.2 vs. 9.0), and overall performance (9.0 vs. 8.6) (Fig. 5).

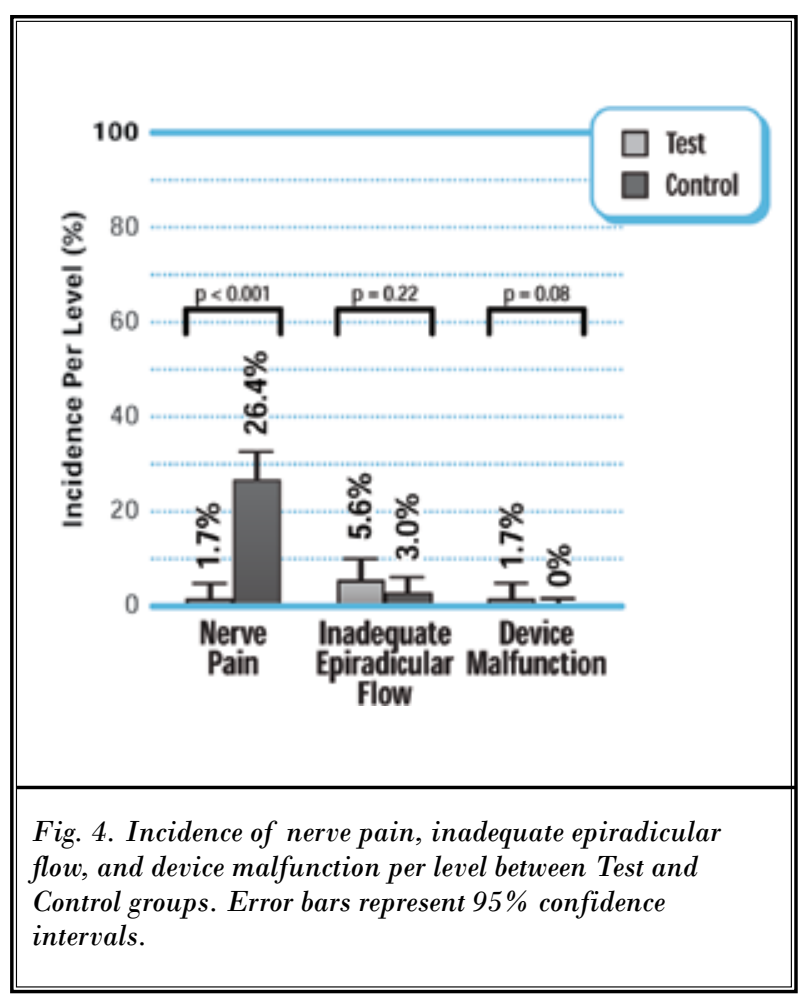

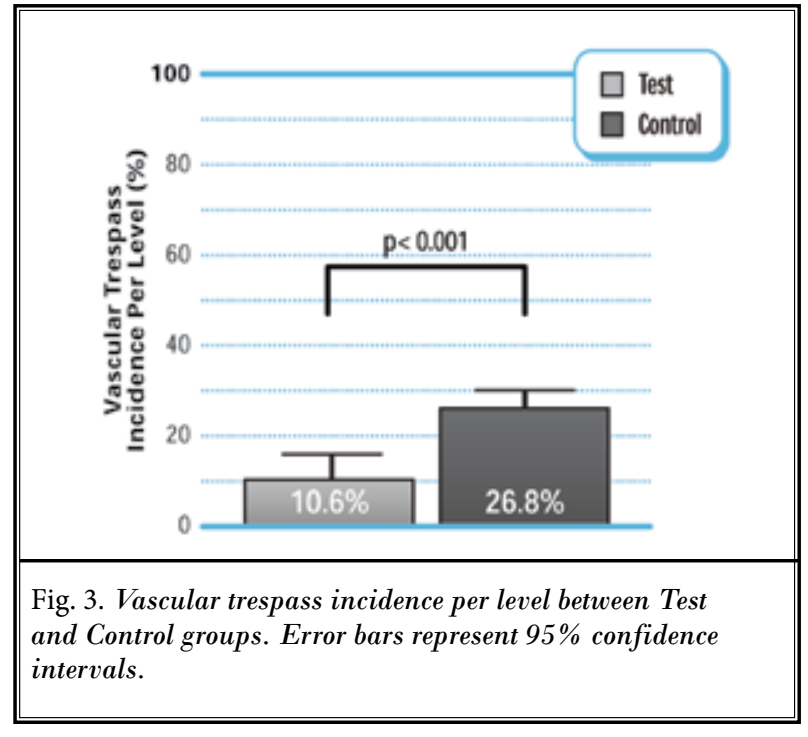

Table 1. Vascular trespass incidence by treated level and study group.

\begin{tabular}{|l|c|c||}
\hline \multirow{2}{*}{ Level } & \multicolumn{2}{|c|}{ Study Group } \\
\cline { 2 - 3 } & Test & Control \\
\hline C1-2 & $(0 / 0)$ & $0 \%(0 / 1)$ \\
\hline C2-3 & $14.3 \%(1 / 7)$ & $50.0 \%(1 / 2)$ \\
\hline C3-4 & $4.5 \%(1 / 22)$ & $25.0 \%(5 / 20)$ \\
\hline C4-5 & $3.3 \%(1 / 30)$ & $26.3 \%(10 / 38)$ \\
\hline C5-6 & $16.2 \%(12 / 74)$ & $22.8 \%(21 / 92)$ \\
\hline C6-7 & $9.3 \%(4 / 43)$ & $31.0 \%(22 / 71)$ \\
\hline C7-T1 & $0 \%(0 / 4)$ & $42.9 \%(3 / 7)$ \\
\hline \hline
\end{tabular}

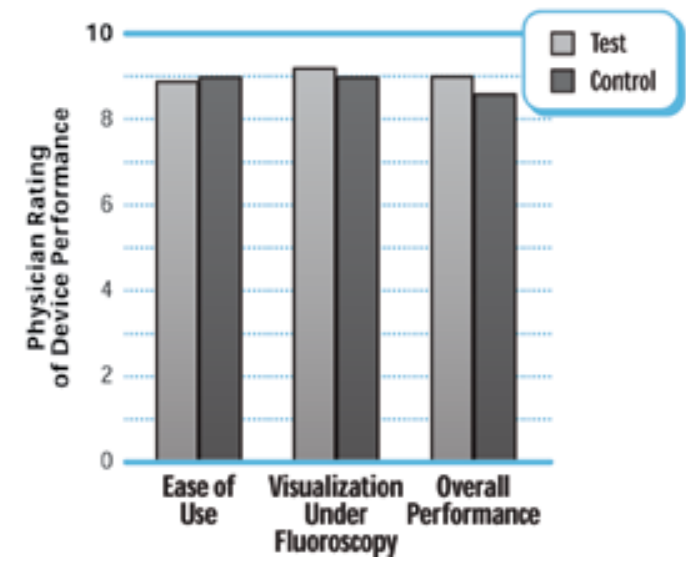

Fig. 5. Physician ratings of device performance between Test and Control groups. 


\section{Adverse Events}

Aside from the pre-defined secondary outcomes, no adverse events were reported in either treatment group in this clinical study.

\section{Discussion}

Transforminal cervical epidural injections are useful in the diagnosis and management of radicular syndromes. Cervical radicular syndromes are often caused by pathology in the foraminal zone of the cervical spine, and transforaminal injection is a reliable method to apply medications directly to the pathology (32).

Recent reports in the literature have highlighted the potential complications and risks of cervical transforaminal injections, although these case reports and surveys do not provide the necessary data to determine causation of the reported complications (35-41). However, it is clear that arterial trespass during cervical transforaminal injection can be accompanied by serious and even fatal consequences. The Trucath Spinal Injection System was developed in an effort to minimize these risks.

The results of this comparative safety trial demonstrate that this novel integrated needle catheter system is a potentially safer alternative to standard spinal injection needles for performing CTFESI. Participants treated with the integrated catheter and needle system had statistically significantly lower rates of intravenous trespass and, more importantly, no intra-arterial trespass was observed. There were also statistically significantly lower rates of operative nerve pain or paresthesia, which may improve procedural patient comfort and, therefore, minimize pain responses that can cause patient movement during needle positioning. The reason for the lower paresthesia rate in the Test group may be due to the blunt, flexible catheter tip that deflects off of neurovascular structures. Needle positioning with this catheter system may further lower the risk of paresthesia since the needle tip is positioned at the lateral margin of the foaramen and, therefore, contact with the nerve root is avoided.

The $10.6 \%$ vascular trespass incidence with the integrated catheter and needle system was notably lower than the $26.8 \%$ incidence in the Control group and the $19.4 \%$ incidence reported by Furman et al (29). The unique design of the integrated catheter and needle system is a major advancement in CTFESI treatment and affords the physician user latitude for procedural and anatomical variability without compromising patient safety. Despite the fact that no serious adverse events were observed in the present study, they remain a distinct, albeit rare, possibility with CTFESI $(30,31)$ especially given the wide variability in cervical vascular anatomy (42).

Vascular trespass may occur more frequently than previously thought. A trial that utilized digital subtraction angiography in addition to real-time fluoroscopy reported vascular trespass in nearly 1 in 3 CESI procedures, an incidence twice as high versus using fluoroscopy alone (43). To the extent that vascular trespass may result in devastating neurologic complications, use of the integrated catheter and needle system may enhance procedural safety, although further investigation is required to demonstrate this benefit.

Although the exact mechanism of neurological injuries during CESI has not been definitively established, the prevailing theory is inadvertent injection of particulate corticosteroid into a vertebral or radicular artery supplying the spinal cord and brainstem, which causes a distal infarct by obstructing the microvasculature. This notion is supported by the association of neurologic injury with methylprednisolone acetate, but not with dexamethasone, when injected into the internal carotid artery of rats (44). Furthermore, Okubadejo and coworkers (45) injected 4 adult pigs with methylprednisolone and 7 with non-particulate steroid (dexamethasone or prednisolone). Pigs who received methylprednisolone suffered diffuse neurological deficits while injection of non-particulate steroids resulted in no adverse sequelae. Finally, several reports have detailed serious neurological injuries and even death following cervical injection of particulate steroids $(35,36,38,46-51)$.

A systematic review reported that the evidence for CTFESI in the management of cervical nerve root pain is strong with demonstrated short-term and long-term improvements $(5,10)$. A separate review found moderate evidence to support CTFESI for cervical radiculopathy $(5,10)$. Nevertheless, it has been suggested that the interlaminar approach is favored by physicians over a transforaminal approach by a 3-to-1 margin (30). The rationale for this observation is unclear but may relate to physician training and background and to reports in the literature that raise warnings regarding CTFESI complications $(33,44,52,53)$. However, a critical review of the literature suggests that complications exist regardless of the approach with no notable differences between transforaminal and interlaminar techniques (33). In fact, there is no strong evidence that a transforaminal approach increases patient risk. 
Kinking of the deployed catheter occurred in 3 $(1.7 \%)$ Test cases. The integrated catheter and needle system utilizes a catheter made from flexible tubing that deploys to a set distance from the distal tip of the needle. If the catheter is advanced into impenetrable tissues, there is potential for the catheter to fold over on itself and occlude flow. However, the clinical importance of this event is minor since no adverse sequelae were associated with these device malfunctions. Continued experience with this integrated catheter and needle system could result in improved techniques that may reduce the frequency of device malfunctions.

This study was not intended to evaluate clinical outcomes beyond the procedure itself. Therefore, comparative patient clinical outcomes with the integrated catheter and needle system versus standard spinal injection needles are not reported herein. Since only a transforaminal approach was utilized during CTFESI, the relative safety of spinal needles used in interlaminal CESI versus the integrated catheter and needle system was not addressed in this study. Treatment allocation was not randomized and, therefore, the outcomes of this study are prone to potential bias effects. Finally, because of the rarity of serious complications with CTFESI, we were unable to determine if the lower vascular trespass rate observed with the integrated catheter and needle system translated into a lower risk for neurological complications.

\section{Conclusion}

Cervical transforaminal epidural injections are a necessary and integral component in the diagno- sis and management of cervical radicular syndromes. Most of these syndromes are caused by pathology in the foraminal zone of the cervical spine. Transforaminal injection is a reliable method to directly apply medications to the foraminal zone of the cervical spine. In this study, use of the Trucath Spinal Injection System resulted in a lower incidence of vascular trespass and nerve pain/paresthesia compared to standard spinal needles for CTFESI in patients with cervical radiculopathy.

\section{Disclosures and Conflicts of Interest}

Author Contributions: All authors had full access to all the data in the study and take responsibility for the integrity of the data and the accuracy of the data analysis. Drs. Kloth, Calodney, Derby, Lagattuta, O’Neill and Yurth conducted the investigation and provided all patient data. Drs. Miller and Block conducted the data analysis and developed the initial manuscript draft. All authors provided revision for intellectual content and final approval of the manuscript.

Funding/Support: This study was supported, in part, by Laurimed (Redwood City, CA) and Smith \& Nephew (Memphis, TN). Smith \& Nephew (Memphis, TN) provided funding assistance to 2 study sites and for manuscript development.

Role of Sponsor: The financial sponsor of this work had no role in the conduct of this study or the management, analysis and interpretation of the data. The sponsor also did not have a role in the preparation or review of the manuscript or the decision to submit.

\section{References}

1. Radhakrishnan K, Litchy WJ, O'Fallon WM, Kurland LT. Epidemiology of cervical radiculopathy. A population-based study from Rochester, Minnesota, 1976 through 1990. Brain 1994; 117:325-335.

2. Carette S, Fehlings MG. Clinical practice. Cervical radiculopathy. $N$ Engl] Med 2005; 353:392-399.

3. Persson LC, Carlsson CA, Carlsson JY. Long-lasting cervical radicular pain managed with surgery, physiotherapy, or a cervical collar. A prospective, randomized study. Spine (Phila Pa 1976) 1997; 22:751-758.

4. Fouyas IP, Statham PF, Sandercock PA. Cochrane review on the role of surgery in cervical spondylotic radiculomyelopathy. Spine (Phila Pa 1976) 2002; 27:736-747.
5. Manchikanti L, Boswell MV, Singh V, Benyamin RM, Fellows B, Abdi S, Buenaventura RM, Conn A, Datta S, Derby R, Falco FJE, Erhart S, Diwan S, Hayek SM, Helm S, Parr AT, Schultz DM, Smith HS, Wolfer LR, Hirsch JA. Comprehensive evidence-based guidelines for interventional techniques in the management of chronic spinal pain. Pain Physician 2009; 12:699-802.

6. Manchikanti L, Boswell MV, Datta S, Fellows B, Abdi S, Singh V, Benyamin RM, Falco FJE, Helm S, Hayek S, Smith HS. Comprehensive review of therapeutic interventions in managing chronic spinal pain. Pain Physician 2009; 12:E123-E198.

7. Manchikanti L, Boswell MV, Singh V, Derby R, Fellows B, Falco FJE, Datta S,
Smith HS, Hirsch JA. Comprehensive review of neurophysiologic basis and diagnostic interventions in managing chronic spinal pain. Pain Physician 2009; 12:E71-E120.

8. Conn A, Buenaventura R, Datta S, Abdi $S$, Diwan S. Systematic review of caudal epidural injections in the management of chronic low back pain. Pain Physician 2009; 12:109-135.

9. Parr AT, Diwan S, Abdi S. Lumbar interlaminar epidural injections in managing chronic low back and lower extremity pain: A systematic review. Pain Physician 2009; 12:163-188.

10. Benyamin RM, Singh V, Parr AT, Conn A, Diwan S, Abdi S. Systematic review of the effectiveness of cervical epidurals in 
the management of chronic neck pain. PPain Physician 2009; 12:137-157.

11. Buenaventura RM, Datta S, Abdi S, Smith HS. Systematic review of therapeutic lumbar transforaminal epidural steroid injections. Pain Physician 2009; 12:233251.

12. Manchikanti L, Singh V, Falco FJE, Cash KA, Pampati V. Evaluation of the effectiveness of lumbar interlaminar epidural injections in managing chronic pain of lumbar disc herniation or radiculitis: A randomized, double-blind, controlled trial. Pain Physician 2010; 13:343-355.

13. Manchikanti L, Cash KA, McManus CD, Pampati V, Benyamin R. Preliminary results of a randomized, double-blind, controlled trial of fluoroscopic lumbar interlaminar epidural injections in managing chronic lumbar discogenic pain without disc herniation or radiculitis. Pain Physician 2010; 13:E279-E292.

14. Manchikanti L, Cash KA, McManus CD, Pampati V, Smith HS. One year results of a randomized, double-blind, active controlled trial of fluoroscopic caudal epidural injections with or without steroids in managing chronic discogenic low back pain without disc herniation or radiculitis. Pain Physician 2011; 14:25-36.

15. Manchikanti L, Cash KA, McManus CD, Pampati V, Smith HS. Preliminary results of randomized, equivalence trial of fluoroscopic caudal epidural injections in managing chronic low back pain: Part 1. Discogenic pain without disc herniation or radiculitis. Pain Physician 2008; 11:785-800.

16. Manchikanti L, Cash KA, McManus CD, Pampati $V$, Benyamin RM. A preliminary report of a randomized double-blind, active controlled trial of fluoroscopic thoracic interlaminar epidural injections in managing chronic thoracic pain. Pain Physician 2010; 13:E357-E369.

17. Manchikanti L, Cash KA, Pampati V, Wargo BW, Malla Y. Cervical epidural injections in chronic discogenic neck pain without disc herniation or radiculitis: Preliminary results of a randomized, double-blind, controlled trial. Pain Physician 2010; 13:E265-E278.

18. Manchikanti L, Cash KA, Pampati V, Wargo BW, Malla Y. The effectiveness of fluoroscopic cervical interlaminar epidural injections in managing chronic cervical disc herniation and radiculitis: Preliminary results of a randomized, double-blind, controlled trial. Pain Physician 2010; 13:223-236.
19. Bush K, Hillier S. Outcome of cervical radiculopathy treated with periradicular/ epidural corticosteroid injections: A prospective study with independent clinical review. Eur Spine J 1996; 5:319-325.

20. Vallee JN, Feydy A, Carlier RY, Mutschler C, Mompoint D, Vallee CA. Chronic cervical radiculopathy: Lateral-approach periradicular corticosteroid injection. Radiology 2001; 218:886-892.

21. Stav A, Ovadia L, Sternberg A, Kaadan M, Weksler N. Cervical epidural steroid injection for cervicobrachialgia. Acta Anaesthesiol Scand 1993; 37:562-566.

22. Cyteval C, Thomas E, Decoux E, Sarrabere MP, Cottin A, Blotman F, Taourel P. Cervical radiculopathy: Open study on percutaneous periradicular foraminal steroid infiltration performed under CT control in 30 patients. AJNR Am J Neuroradiol 2004; 25:441-445.

23. Kolstad F, Leivseth G, Nygaard OP. Transforaminal steroid injections in the treatment of cervical radiculopathy. A prospective outcome study. Acta Neurochir (Wien) 2005; 147:1065-1070; discussion 1070 .

24. Ferrante FM, Wilson SP, lacobo C, Orav EJ, Rocco AG, Lipson S. Clinical classification as a predictor of therapeutic outcome after cervical epidural steroid injection. Spine (Phila Pa 1976) 1993; 18:730-736.

25. Slipman CW, Lipetz JS, Jackson HB, Plastaras CT, Vresilovic EJ. Outcomes of therapeutic selective nerve root blocks for whiplash induced cervical radicular pain. Pain Physician 2001; 4:167-174.

26. Slipman CW, Lipetz JS, Jackson HB, Rogers DP, Vresilovic EJ. Therapeutic selective nerve root block in the nonsurgical treatment of atraumatic cervical spondylotic radicular pain: A retrospective analysis with independent clinical review. Arch Phys Med Rehabil 2000; 81:741-746.

27. Slipman CW, Lipetz JS, DePalma MJ, Jackson HB. Therapeutic selective nerve root block in the nonsurgical treatment of traumatically induced cervical spondylotic radicular pain. Am J Phys Med Rehabil 2004; 83:446-454.

28. Lin EL, Lieu V, Halevi L, Shamie AN, Wang JC. Cervical epidural steroid injections for symptomatic disc herniations. J Spinal Disord Tech 2006; 19:183-186.

29. Furman MB, Giovanniello MT, O'Brien EM. Incidence of intravascular penetration in transforaminal cervical epidural steroid injections. Spine (Phila Pa 1976)
2003; 28:21-25.

30. Derby R, Lee SH, Kim BJ, Chen Y, Seo KS. Complications following cervical epidural steroid injections by expert interventionalists in 2003. Pain Physician 2004; 7:445-449.

31. Ma DJ, Gilula LA, Riew KD. Complications of fluoroscopically guided extraforaminal cervical nerve blocks. An analysis of 1036 injections. J Bone Joint Surg Am 2005; 87:1025-1030.

32. Huston CW. Cervical epidural steroid injections in the management of cervical radiculitis: Interlaminar versus transforaminal. A review. Curr Rev Musculoskelet Med 2009; 2:30-42.

33. Scanlon GC, Moeller-Bertram T, Romanowsky SM, Wallace MS. Cervical transforaminal epidural steroid injections: More dangerous than we think? Spine (Phila Pa 1976) 2007; 32:1249-1256.

34. Rozin L, Rozin R, Koehler SA, Shakir A, Ladham S, Barmada M, Dominick J, Wecht $\mathrm{CH}$. Death during transforaminal epidural steroid nerve root block $\left(C_{7}\right)$ due to perforation of the left vertebral artery. Am J Forensic Med Pathol 2003; 24:351-355.

35. Ruppen W, Hugli R, Reuss S, Aeschbach A, Urwyler A. Neurological symptoms after cervical transforaminal injection with steroids in a patient with hypoplasia of the vertebral artery. Acta Anaesthesiol Scand 2008; 52:165-166.

36. Lee JH, Lee JK, Seo BR, Moon SJ, Kim $\mathrm{JH}, \mathrm{Kim} \mathrm{SH}$. Spinal cord injury produced by direct damage during cervical transforaminal epidural injection. Reg Anesth Pain Med 2008; 33:377-379.

37. Shakir A, Kimbrough DA, Mehta B. Postherpetic neuralgia involving the right $\mathrm{C}_{5}$ dermatome treated with a cervical transforaminal epidural steroid injection: A case report. Arch Phys Med Rehabil 2007; 88:255-258.

38. Muro K, O'Shaughnessy B, Ganju A. Infarction of the cervical spinal cord following multilevel transforaminal epidural steroid injection: Case report and review of the literature. J Spinal Cord Med 2007; 30:385-388.

39. Glaser SE, Falco FJE. Paraplegia following a thoracolumbar transforaminal epidural steroid injection. Pain Physician 2005; 8:309-314.

40. Glaser SE, Shah RV. Root cause analysis of paraplegia following transforaminal epidural steroid injections: The 'unsafe' triangle. Pain Physician 2010; 13:237-244. 
41. Helm S, Hayek S, Benyamin RM, Manchikanti L. Systematic review of the effectiveness of thermal annular procedures in treating discogenic low back pain. Pain Physician 2009; 12:207-232.

42. Huntoon MA. Anterior spinal artery syndrome as a complication of transforaminal epidural steroid injections. Semin Pain Med 2004; 2:204-207.

43. McLean JP, Sigler JD, Plastaras CT, Garvan CW, Rittenberg JD. The rate of detection of intravascular injection in cervical transforaminal epidural steroid injections with and without digital subtraction angiography. PM R 2009; 1:636642.

44. Dawley JD, Moeller-Bertram T, Wallace MS, Patel PM. Intra-arterial injection in the rat brain: Evaluation of steroids used for transforaminal epidurals. Spine (Phila Pa 1976) 2009; 34:1638-1643.
45 Okubadejo GO, Talcott MR, Schmidt RE, Sharma A, Patel AA, Mackey RB, Guarino AH, Moran CJ, Riew KD. Perils of intravascular methylprednisolone injection into the vertebral artery. An animal study. J Bone Joint Surg Am 2008; 90:1932-1938.

46. Ludwig MA, Burns SP. Spinal cord infarction following cervical transforaminal epidural injection: A case report. Spine (Phila Pa 1976) 2005; 30:E266-268.

47. Baker R, Dreyfuss $P$, Mercer S, Bogduk N. Cervical transforaminal injection of corticosteroids into a radicular artery: $\mathrm{A}$ possible mechanism for spinal cord injury. Pain 2003; 103:211-215.

48. Rathmell JP, Aprill C, Bogduk N. Cervical transforaminal injection of steroids. Anesthesiology 2004; 100:1595-1600.

49. Rathmell JP, Benzon HT. Transforaminal injection of steroids: Should we continue? Reg Anesth Pain Med 2004; 29:397399.

50. Beckman WA, Mendez RJ, Paine GF, Mazzilli MA. Cerebellar herniation after cervical transforaminal epidural injection. Reg Anesth Pain Med 2006; 31:282285.

51. Glaser SE, Falco F. Paraplegia following a thoracolumbar transforaminal epidural steroid injection. Pain Physician 2005; 8:309-314.

52. Dominguez E. The practice of cervical transforaminal injection of steroids deserves more scrutiny. Pain Physician 2005; 8:323-324.

53. Rathmell JP. Toward improving the safety of transforaminal injection. Anesth Analg 2009; 109:8-10. 
